\title{
Pistil traits and flower fate in apricot (Prunus armeniaca)
}

J. Rodrigo $^{1}$, M. Herrero ${ }^{2} \&$ J. I. Hormaza ${ }^{3}$

${ }^{1}$ Unidad de Fruticultura, CITA-DGA, Avda. Montañana 930, 50059 - Zaragoza, Spain

${ }^{2}$ Departamento de Pomología, EE Aula Dei, CSIC, Apartado 202, 50080 - Zaragoza, Spain

${ }^{3}$ Departamento de Fruticultura Subtropical y Fitopatología. EE La Mayora, CSIC, 29760 -

Algarrobo-Costa, Málaga, Spain

Running page heading: Pistil traits and flower fate in apricot

Corresponding author:

Javier Rodrigo

Unidad de Fruticultura

CITA-DGA

Avda. Montañana 930

50059 - Zaragoza

Spain

Email: jrodrigo@aragon.es 


\begin{abstract}
Although pollination is essential for both seed and fruit set in most Angiosperms, even after an adequate pollination only a fraction of the flowers develop into fruits. The role played by floral traits on reproductive success is well known, but the possible influence of pistil traits has been overlooked, probably due to the difficulty of non-destructive pistil examination. The aim of this work is to examine the influence of several pistil traits on reproductive success in apricot (Prunus armeniaca). For this purpose, in a population of individually labelled flowers, the styles were cut off once the pollen tubes had reached the ovary but prior the achievement of fertilization. This approach allowed relating several morphological and physiological pistil parameters in the dissected styles and stigmas to the subsequent set or abscission of the corresponding ovary that remained in the plant. Under the same pollination conditions, the flowers that finally set a fruit show a larger stigmatic area and a higher number of pollen grains, pollen tubes growing along the style, and xylem vessels surrounding the transmitting tissue than flowers that abscise before the establishment of fruit set. Furthermore, starch is present in the transmitting tissue of the style in all the flowers that develop into fruits, but only in half of the flowers that abscise. The examined pistil traits established prior to fertilization are related to flower fate suggesting that the capacity of a flower to become a fruit could be preconditioned at anthesis.
\end{abstract}

Keywords: Fruit set, pollen grains, pollen tubes, starch, stigma, style. 


\section{Introduction}

In most angiosperms, flowers must be pollinated to set seeds and fruits and, hence, pollination is the primary step in reproductive success (Stephenson, 1981). During the pollination process, the stigma must receive enough pollen to reach a minimum threshold for fertilizing sufficient ovules to elicit fruit set (Stephenson, 1981) and, consequently, the amount of pollen grains received in the stigma plays a key role in the reproductive success (Falque et al., 1995; Wilcock \& Neiland, 2002; Cane \& Schiffhauer, 2003). However, even after an adequate pollination, only a portion of the flowers develop into fruits (Charlesworth, 1989), indicating that other factors inherent to the flower itself could play a role in reproductive success. In fact, maternal investment, mainly after pollination, usually exceeds paternal investment because the maternal sporophyte has to provide resources to the female gametophyte and the developing seeds and fruits (Stephenson \& Bertin, 1983). Different hypotheses have been proposed to explain the surplus production of flowers compared to final fruit set (for reviews see Ayre \& Whelan, 1989; Guitian, 1993).

Stigma and style traits have received much less attention than the 'attractiveness' floral traits in order to explain the reasons behind reproductive success in plants, and often the pistil has been identified as a passive structure that provides an arena for pollen tube growth and pollen competition. Nevertheless, evidence is accumulating suggesting that the pistil is an active structure that supports pollen germination in the stigma and pollen tube growth along the style towards the ovule and provides an adequate environment, nutrition and directional cues for fertilization to take place (Herrero \& Hormaza, 1996; Herrero, 2000; Herrero, 2003). While the wide variety of stigma (Heslop-Harrison, 2000) and style (Barret et al., 2000) morphologies reflect the different pollination mechanisms found among Angiosperms, information is lacking about the significance of the variation of pistil traits among flowers of the same plant. This is 
due to the fact that most studies on flower and fruit abscission have been performed without discriminating the differences among individual flowers.

The main limitation to examine the effect of pistil traits of individual flowers on fertilization success and fruit set is the difficulty to relate the female attributes of individual flowers at anthesis to subsequent developmental processes, since either the destruction of samples is required to study the female floral morphology (Pimienta et al., 1983; Williams \& Conner, 2001; Bernasconi et al., 2007), or the analyses are performed when the flower has finally abscised or set into a fruitlet and the pistil structures have degenerated or changed compared to their initial stage at flowering (Sedgley, 1980). As an alternative, in this work the styles were cut off above the ovary after the living tip of the pollen tubes has passed through, but before the achievement of fertilization, which subsequently occurred unaltered. By this method, the stigma and style traits of individual flowers could be related to the subsequent fate of the ovaries that remained in the plant. A similar approach has been previously used to evaluate the effect of pollination intensity on fruiting (Falque et al., 1995).

The objective of this work is to determine whether pistil traits influence the reproductive success in apricot (Prunus armeniaca L.). Apricot has several advantages to perform this kind of experiments: the style and the ovary can be easily distinguished, it produces single-seeded fruits avoiding the problems of differential fruit set associated with the number of fertilized seeds per fruit, it produces energetically costly fleshy fruits with a high flower to fruit investment and it is a histerant species where flowering takes place in the absence of leaves and, consequently, at the expense of pre-stored reserves in the flower. The gynoecium of apricot, as in other Prunus species, is unicarpellate (Sterling, 1964). The stigma of apricot is papillated and wet and the style shows a compact transmitting tissue enveloped by vascular bundles (Rodrigo \& Herrero, 2002a). Two ovules are present in the 
ovary although usually only one seed is produced (Rodrigo \& Herrero, 1998). Pollen grains germinate on the moist surface of the stigma within one day after pollination. The pollen tube penetrates into the stigma between the papillae, reaches the transmitting tissue and grows along the style in the following days. Pollen tube growth along the style takes 3-4 days. Upon arrival at the ovary, the pollen tubes traverse the obturator around 5 days after pollination, penetrate into the ovule through the micropyle and finally enter the nucellus to reach the embryo sac and achieve fertilization around 7 days after pollination (Rodrigo \& Herrero, 2002a). To explore the implications of the stigma and style traits in the development of the ovaries that remain in the tree and the subsequent fruit set or abscission, several morphological and physiological pistil parameters have been analysed in the styles and stigmas dissected. To relate the microscopical observations of pistil traits with the behaviour of the developing ovaries, fruit set and fruit abscission have also been sequentially examined in the field. 


\section{Materials and methods}

Plant material

Flowers from three clonal trees of the self-incompatible apricot 'Moniqui' were used in this experiment. The study was performed in two synchronized populations of flowers, one consisting of flowers pollinated with compatible pollen and the other of non pollinated flowers. In order to synchronize developmental processes, only flowers at the same developmental stage (balloon stage which occurs one day prior to anthesis) were left on randomly selected branches in each tree; previously opened flowers and younger buds were removed. To ensure that flowers were under the same pollination conditions, flowers at balloon stage were emasculated and their petals removed one day before anthesis to make the flowers unattractive to insects and prevent free pollination (Free, 1964). A total of 960 emasculated flowers were labelled individually with 18x29 mm strung tickets. At anthesis, a group of 480 flowers was left unpollinated and another group of 480 flowers was pollinated with compatible pollen from apricot 'Canino' (Rodrigo \& Herrero, 1996) that was previously obtained from flowers at the balloon stage by removing the anthers and placing them at room temperature on paper in the laboratory. Pollen was sieved 24 hours later through a $0.26 \mathrm{~mm}$ mesh and frozen at $-20^{\circ} \mathrm{C}$ until required.

To establish the time of pollen tube arrival at the base of the style, a preliminary experiment was performed in which emasculated pollinated flowers were daily fixed at 1,2 , 3, 4, 5 and 6 days after pollination and examined under the microscope following the methodology described below. When pollen tubes had reached the base of the style in all the pollinated flowers, between 5 and 6 days after anthesis (Fig. 1), but before the achievement of fertilization (Rodrigo \& Herrero, 2002a), the styles were cut off from the ovaries of the 
960 labelled flowers. For both days 5 and 6 after anthesis, 240 pollinated and 240 non pollinated styles were dissected and fixed individually in FAA [70\% ethanol: glacial acetic acid: formalin (18:1:1, v/v)] (Johansen, 1940). Several morphological and physiological flower parameters were analysed in the styles and stigmas dissected under the microscope. To relate the microscopical observations of the stigma and the style in each pistil with the behaviour of the corresponding ovaries that remained in the trees, fruit set and fruit abscission were sequentially examined in the field. To characterise the fruit abscission pattern and ascertain final fruit set, the labels of abscised flowers and developing fruits in both groups of pollinated and non pollinated flowers were recorded weekly from anthesis to maturity. Fruit abscission and fruit set were also monitored in three additional groups of flowers. A total of 400 pollinated and 400 non pollinated flowers were left in the same conditions than treated flowers, but without dissection of the styles. Another group of 550 non-emasculated and open-pollinated flowers was left as control. For this purpose, weekly counts of the three groups of flowers and developing fruits were made from anthesis to harvest.

Determination of stigma size

After fruit maturity, when the fate of each controlled flower was known, about 55 styles previously fixed of each population of set and abscised flowers were examined. To determine stigmatic area, stigmas were dissected from the styles and individually rehydrated by washing with distilled water three times, one hour each wash, and maintained $24 \mathrm{~h}$ in distilled water. Each rehydrated stigma was placed on a glass slide with its stigmatic surface in contact with the slide and observed under a binocular microscope (Wild M8, Heerbrugg, Switzerland). The images were collected using a camera attached to the binocular 
microscope and processed using a Quantiment 570 Image Analysis System (Leica, Cambridge, England). Stigma size values were obtained by measuring the area of the collected image. To overcome possible distortions, at least two measurements of each preparation were taken.

Microscope preparations

After stigma size determination, pollen germination was monitored on squash preparations of the same stigmas previously autoclaved at $1 \mathrm{~kg} / \mathrm{cm}^{2}$ for $5 \min$ in $5 \%$ (w/v) sodium sulphite to soften the tissues (Jefferies \& Belcher, 1974) and stained with $0.1 \%$ (v/v) aniline blue in $\mathrm{K}_{3} \mathrm{PO}_{4} 0.1 \mathrm{~N}$ (Linskens \& Esser, 1957). The number and percentage of germinating and non-germinating pollen grains was recorded at each stigma. Pollen tube growth was monitored with the same staining procedure used to observe pollen germination. The total number and the percentage of pollen tubes were recorded at the transmitting tissue entrance, at one quarter, one half and three quarters of the way down the style and at the base of the style.

In a different batch of flowers, the presence of starch and the number of cells and xylem vessels were monitored in sections of the base of the styles. For this purpose, a transversal section of $1-2 \mathrm{~mm}$ at the base of the style was dissected in each style, individually dehydrated in a tertiary butyl alcohol series (70\%, 85\%, 95\% and 100\%), embedded in paraffin wax and sectioned at $10 \mu \mathrm{m}$ in a rotary microtome (Reichert-Jung 1130/Biocut, Heidelberg, Germany). The preparations were first stained with $\mathrm{I}_{2} \mathrm{KI}$ for starch reserves (Johansen, 1940) and then with $0.1 \%$ aniline blue in $\mathrm{K}_{3} \mathrm{PO}_{4} 0.1 \mathrm{~N}$ for callose (Linskens \& Esser, 1957) and with $0.01 \%$ (w/v) acridine orange in $0.03 \mathrm{M} \mathrm{K}_{3} \mathrm{PO}_{4}$ (Dudley 
et al., 1987) to count the number of xylem vessels and, finally, with calcofluor white for cellulose (Hughes \& McCully, 1975) to count the number of cells.

All the preparations were observed under an Ortholux II microscope (Leitz, Wetzlar, Germany). Fluorescent preparations were viewed with UV epifluorescence, using a BP 355425 exciter filter and an LP 460 barrier filter for preparations stained with aniline blue and calcofluor, and a BP 450-490 exciter filter and an LP 515 barrier filter for preparations stained with acridine orange.

Statistical analyses

Statistical analyses were performed with SPSS 12.0 statistical software (SPSS Inc., Chicago, USA). MANOVAs were used to ascertain possible differences among trees and flower fate. Thus, Nested-MANOVA was performed with each flower nested to its corresponding tree, and differences on stigmatic area, number of pollen grains and number of germinated pollen grains were analyzed depending on the nested term [flower fate (tree)]. Another MANOVA was performed to analyse the effect of flower fate on the same variables followed by oneway ANOVAs to ascertain the effect of flower fate on each variable separately. Additionally, Pearson correlation coefficients were computed for the traits studied in the same stigmas.

Backward stepwise multiple regression analysis using Generalized Linear Models was performed to ascertain which of the traits studied in the same flowers (stigmatic area, number of pollen grains, number of germinating pollen grains and number of pollen tubes at the different style sections) best explained the fate of flowers. Analysis was done assuming a binomial distribution of the dependent variable (fate of the flower), and a logit relationship 
between the mean of the response variable and the linear combination of the explanatory variables (Breslow, 1996).

The effect of flower fate on number of cells and xylem vessels was analyzed with MANOVA, after checking for redundancy with a correlation analysis. Finally, univariate tests were done after MANOVA to determine the effect of flower fate on each of the two variables separately. 


\section{Results}

Pollen tube growth along the style took 3-4 days (Fig. 1A) and all the pistils presented some pollen tubes at the base of the style 4 days after pollination (Fig. 1B). To relate the microscopical observations to the subsequent fruit set, flower and fruit abscission were recorded weekly until harvest (Fig. 2). While drop of open- and hand- pollinated flowers stopped between 4 and 5 weeks after anthesis, drop of unpollinated flowers was completed at this time (Fig. 2A, B). Although the percentage of fruit set is highly variable among years and cultivars in apricot, this pattern of fruit abscission is consistent with previous reports in this species (Rodrigo \& Herrero, 2002a). No significant differences were found between the percentages of fruit set in the flowers whose styles were removed the days 5 (Fig. 2C, D) and 6 after anthesis (Fig. 2E, F). The two treatments showed very similar percentage of fruit survival (53\% in day 5 and $55 \%$ in day 6). Since 4 days after pollination all the flowers showed pollen tubes at the base of the style and no differences in fruit set were found between the two treatments (removal of the style at day 5 and 6 after pollination), the population of flowers with styles dissected 5 days after pollination was selected for microscopic analyses, since the dissected styles were better preserved than those removed one day later. The style removal treatment resulted in a slight reduction in the percentage of fruit survival at maturity (53-55\%) compared to the control (63\%). Several factors could be involved in this reduction: among them, some damage could be caused to the ovary in some flowers during the style removal process similarly to that caused by emasculation (Hedhly et al., in press) or the possibility that the style was dissected in some pistils before the arrival of enough pollen tubes to the ovary. In any case, fruit set in both populations of flowers with styles dissected were higher than in open-pollinated flowers (31\%) (Fig. 2).

In the dissected styles and stigmas, the stigmatic area was measured and the number of pollen grains and pollen tubes along the style was evaluated. To assess whether differences in 
the analysed parameters were related to the maternal plant, a nested MANOVA was performed. No significant differences were recorded among the three clonal trees for the variables stigmatic area, number of pollen grains at the stigma and number of germinating pollen grains. Both the nested term [flower fate (tree)] (Wilks value=0.95, $\mathrm{p}=0.60$ ) and the independent variable tree (Wilks value $=0.89, \mathrm{p}=0.27$ ) were non-significant, indicating that the behaviour of each of the variables tested was similar among trees. Thus, data from flowers of the three clonal trees used in the experiment were pooled in the subsequent analyses. On the other hand, significant differences depending on flower fate were recorded on the same variables after MANOVA (Wilks value $=0.92, \mathrm{p}=0.03$ ). The ANOVAs performed to ascertain the effect of flower fate on each variable showed significant differences between both populations of set and abscised flowers in stigmatic area, number of pollen grains at the stigma and number of germinated pollen grains (Table 1) and these differences follow the same pattern (Fig. 3). The comparison of stigma traits shows significant and positive correlations at the $95 \%$ confidence level between stigma size and number of pollen grains (0.44), stigma size and germinated pollen grains (0.42) and total pollen grains and germinated pollen grains $(0.91, \mathrm{~N}=106)$.

Stigmatic area of pollinated pistils follows a normal distribution, ranging from 0.47 to $0.88 \mathrm{~mm}^{2}$. This variation in size appears to be related to the differences observed among pistils in fruit survival, since the percentage of fruit set of each class increases from $0 \%$ in the stigmas with an area up to $0.55 \mathrm{~mm}^{2}$, until more than $60 \%$ in the stigmas with an area larger than $0.70 \mathrm{~mm}^{2}$ (Fig. 4A). Likewise, the number of pollen grains on the stigma follows a normal distribution, ranging from 5 to 233 pollen grains. The percentage of fruit set increases with the number of pollen grains from $0 \%$ in the stigmas with up to 30 pollen grains until more than $60 \%$ in the stigmas with more than 90 pollen grains (Fig. 4B).

The apricot style shows a compact transmitting tissue enveloped by a cortical tissue (Fig. 5A) and vascular bundles (Fig. 5B). The number of pollen tubes were recorded at the 
transmitting tissue entrance, at one quarter, one half (Fig. 5C) and three quarters of the way down the style and at the base of the style (Fig. 5D). A reduction in the number of pollen tubes growing down the style was recorded in both populations of set and abscised flowers (Fig. 6). The differences in the number of germinating pollen grains on the stigma between set and abscised flowers are maintained when the pollen tubes penetrate the transmitting tissue and grow along the style. Thus, while the number of pollen tubes is significantly higher in the set flowers in each level of the style, the pattern of reduction is very similar for the two populations of flowers and, finally, 9.1 and 6.9 pollen tubes penetrate in the ovary in set and abscised flowers, respectively (Student's test: $p=0.003$, Fig. 6A). Thus, the percentage of pollen tubes traversing each pistilar section (based on the initial number of pollen tubes recorded at the transmitting tissue) is rather constant along the style regardless of the initial number of pollen tubes (Fig. 6B). Backward stepwise multiple regression analysis results indicate that only stigmatic area and number of pollen tubes at the base of the style are kept in the model; therefore, these two variables can be considered as the best predictors for flower fate (Table 2).

The observation of the stylar sections under the microscope showed that starch is present in the base of the style in all the flowers that develop into fruits but only in approximately half of the abscised flowers (Table 3). Likewise, MANOVA analysis revealed that the number of cells and xylem vessels depending on flower fate was only marginally significant (Wilks value $=0.6, \mathrm{p}=0.05$ ). Therefore, univariate analyses were done for each of the variables separately. The results showed that the number of xylem vessels surrounding the transmitting tissue is significantly larger in set than in abscised flowers but no significant differences in the number of cells in the transversal section of the base of the style are recorded between set and abscised flowers (Table 3). 


\section{Discussion}

Pistil traits established prior to fertilization showed a relationship with the subsequent flower fate. Thus, under the same pollination conditions, the flowers that finally set fruits show a larger stigmatic area and a higher amount of pollen grains at the stigma, of pollen tubes growing along the style, and of xylem vessels surrounding the transmitting tissue in the days following anthesis than those flowers that abscise before the establishment of fruit set. Furthermore, the nutritional status of the pistil also appears to be related to fruit set, since starch is present in the transmitting tissue of the style in all the flowers that develop into fruits, but only in half of the flowers that abscise.

The flowers that successfully developed into fruits presented a significant higher pollen load than the flowers that abscised prematurely. A large reduction in the number of pollen tubes occurred as they grew along the styles, similarly to previous reports in other Prunus species (Pimienta et al., 1983; Hormaza \& Herrero, 1996; Hedhly et al., 2005a). But the clear differences between set and abscised flowers in the number of pollen grains at the stigma are maintained in the number of pollen tubes that reach each pistilar level, being reduced by the same proportion in set and abscised flowers. This confirms previous indications that pollen-pistil interaction based on the genotypes of both the pollen and the pistil may play a major role in the regulation of pollen tube attrition and that it could be superimposed over physical and nutritional differences among pistils (Hormaza \& Herrero, 1996; Hedhly et al., 2005b). Since each style in apricot usually serves a single-seeded fruit, theoretically just one pollen tube at the ovary could be sufficient for seed and fruit set. However, although in a lower number than in set flowers, an average of 7 pollen tubes reached the ovary in abscised flowers suggesting that while the arrival of pollen tubes to the ovary is a requirement, it does not appear to be sufficient for a flower to develop into a fruit, supporting the idea that other factors may be involved in determining fruit set in apricot 
(Rodrigo \& Herrero, 2002a). Pollination regulates the hormonal status of the pistil (Kovaleva \& Zakharova, 2003), and the number of pollen tubes has been correlated to the levels of a hormone-precursor in the style (Weterings et al., 2002). Thus, the differences in the number of pollen tubes reported herein between set and abscised flowers could be related to possible differences in the amount of hormones in the pistil. While this point warrants evaluation, a direct relationship is observed among the number of both pollen grains and pollen tubes and the stigmatic area, since all the flowers analysed were pollinated under the same conditions. Thus, it appears clear that the final number of male gametophytes reaching the ovary depends mainly on female traits. A similar relationship has been recently reported between style length and number of pollen tubes reaching the ovule in Prunella grandiflora (Bernasconi et al., 2007).

Stigma size is a key factor in reproductive success, since stigmas have to be large enough to accommodate sufficient pollen grains to account for the fertilization of the available ovules (Cruden, 2000). While differences in stigmatic size have been reported among different species (Cruden \& Miller-Ward, 1981; Shykoff, 1992; Bigazzi \& Selvi, 2000; Cruden, 2000; Yang et al., 2002), among genotypes of the same species (Hedhly et al., 2005b), and among trees of the same genotype under different conditions (Sukhvibul et al., 1999) or seasons (Buszard \& Schwabe, 1995), results herein show differences in stigmatic area among flowers in the same genotype despite the fact that the flowers analysed were synchronized and developed under the same conditions. Moreover, the stigmas are not equally successful in capturing pollen and some stigmas appear to gather approximately twice the number of pollen grains than others. Thus, there is a positive correlation between the stigmatic area and the number of pollen grains the stigmas can receive and, consequently, the number of pollen tubes growing in the style. Furthermore, a direct 
relationship between stigmatic area and flower quality was found, showing that a minimum stigmatic area is necessary for a flower to develop into a fruit.

However, differences in stigma size among flowers cannot entirely explain why some flowers abscise while others continue growing. Since stigma morphology has been related to other morphological aspects of floral biology (Yang et al., 2002), stigma size could be also associated to other flower traits. Flower quality has been empirically related to flower traits and differences in size among good and poor quality flowers are often reported in different experiments in several tree species regardless of the reasons for the differences in flower quality, such as nitrogen summer applications (Williams, 1965), previous crop load (Buszard \& Schwabe, 1995), tree and wood age (Robbie \& Atkinson, 1994), orientation of branches (Robbie et al., 1993), stresses during carpel initiation (Lamp et al., 2001) or warm pre-blossom temperatures (Rodrigo \& Herrero, 2002b). In this work, the flowers that finally set fruits showed a significantly larger stigma size, amount of starch reserves in the transmitting tissue of the style and the number of xylem vessels surrounding the transmitting tissue. This suggests that physiological mechanisms in addition to morphological stigma traits differ between set and abscised flowers.

In $P$. armeniaca, like in other histerant species where flowering takes place prior to leaf emergence, a flower lifespan occurs in the absence of new photoassimilates and at the expense of pre-stored reserves. Previous reports suggest that the starch stored in the flower at anthesis is involved in the establishment of fruit set. Thus, the presence or absence of starch in the ovary and in the ovules has a key influence on fertilization and fruit set (Rodrigo \& Herrero, 1998; Rodrigo et al., 2000; Lebon et al., 2004), since starch supports early ovary development (Rodrigo et al., 2000) and the starch within the ovule is involved in the development of both the ovular structures and the embryo (Arbeloa \& Herrero, 1991; Rodrigo \& Herrero, 1998; Cerovic et al., 1999; Kuhn, 2006). Furthermore, differences in the 
amount of starch have been reported among flowers of genotypes with different resistance to flower abscission (Lebon et al., 2004) and among flowers of the same genotype (Rodrigo et al., 2000). This could account for the different behaviour of flowers and could influence the chances of a pollinated flower to develop into a fruit. The presence of starch in the transmitting tissue of the style in all the set flowers together with the fact that all the flowers without starch finally abscise suggest that starch remains in the style after the pollen tubes have passed through in those flowers with better nutritional status at anthesis. Thus, starch content could be a good indicator of flower quality.

The method used here involving hand-pollination and subsequent style removal has proved to be useful to establish relationships among both pistil traits and pollen performance with the subsequent fate of the ovaries that remain in the tree. The results obtained in this work suggest that the capacity of a flower to become a fruit would be preconditioned by preestablished pistil traits. Those pistil traits would influence the number of pollen grains that germinate on the stigma and, consequently, "better" pistils would increase pollen competition by increasing the number of pollen tubes. Thus, the fruits that remain in the tree could eventually be the result of higher pollen competition during the progamic phase in flowers that present morphological and physiological advantageous pistil traits.

\section{Acknowledgements}

The authors thank Reyes López for technical assistance and Marta Montserrat for help with the statistical analyses. Financial support for this research was provided by Ministerio de Ciencia e Innovación-FEDER, (Plan Nacional de Investigación Científica, Desarrollo e Innovación Tecnológica, Project grants: AGL2006-13529-C02-00/AGR and AGL200760130/AGR) and by Grupo de Excelencia A-43 (Gobierno de Aragón). 


\section{References}

Arbeloa A., Herrero M. (1991) Development of the ovular structures in peach [Prunus persica (L.) Batsch]. New Phytologist, 118, 527-534.

Ayre D.J., Whelan R.J. (1989) Factors controlling fruit-set in hermaphroditic plants - studies with the Australian Proteaceae. Trends in Ecology \& Evolution, 4, 267-272.

Barrett S.C.H., Jesson L.K., Baker A.M. (2000) The evolution and function of stylar polymorphisms in flowering plants. Annals of Botany, 85 (Suppl. A), 253-265.

Bernasconi G., Lang D.J., Schmid B. (2007) Microgametophyte population sizes and plant reproductive output in the insect-pollinated Prunella grandiflora (Lamiaceae). New Phytologist, 173, 393-400.

Bigazzi M., Selvi F., (2000) Stigma form and surface in the tribe Boragineae (Boraginaceae): micromorphological diversity, relationships with pollen, and systematic relevance. Canadian Journal of Botany, 78, 388-408.

Breslow N.E. (1996) Generalized linear models: checking assumptions and strengthening conclusions. Statistica Applicata, 8, 23-41.

Buszard D., Schwabe W.W. (1995). Effect of previous crop load on stigmatic morphology of apple flowers. Journal of the American Society for Horticultural Science, 120, 566-570.

Cane J.H., Schiffhauer D. (2003) Dose-response relationships between pollination and fruiting refine pollinator comparisons for cranberry (Vaccinium macrocarpon [Ericaceae]). American Journal of Botany, 90, 1425-1432.

Cerovic R., Micic N. (1999) Functionality of embryo sacs as related to their viability and fertilization success in sour cherry. Scientia Horticulturae, 79, 227-235.

Charlesworth D. (1989) Why do plants produce so many more ovules than seeds? Nature, 338, 21-22. 
Cruden R.W. (2000) Pollen grains: why so many? Plant Systematics and Evolution, 222, 143-165.

Cruden R.W., Millerward S. (1981) Pollen-ovule ratio, pollen size, and the ratio of stigmatic area to the pollen-bearing area of the pollinator - an hypothesis. Evolution, 35, 964974.

Dudley M.E., Jacobs T.W., Long S.R. (1987) Microscopic studies of cell divisions induced in alfalfa roots by Rhizobium meliloti. Planta, 171, 289-301.

Falque M., Vincent A., Vaissiere B.E., Eskes A.B. (1995) Effect of pollination intensity on fruit and seed set in cacao (Theobroma cacao L.). Sexual Plant Reproduction, 8, 354-360.

Free J.B. (1964) Comparison of the importance of insect and wind pollination of apple trees. Nature, 201, 726-727.

Guitian J. (1993) Why Prunus mahaleb (Rosaceae) produces more flowers than fruits? American Journal of Botany, 80, 1305-1309.

Hedhly A., Hormaza J.I., Herrero M. (2005 a) The effect of temperature on pollen germination, pollen tube growth, and stigmatic receptivity in peach. Plant Biology, 7, 476-483.

Hedhly A., Hormaza J.I., Herrero M. (2005 b) Influence of genotype-temperature interaction on pollen performance. Journal of Evolutionary Biology, 18, 1494-1502.

Hedhly, A., Hormaza J.I., Herrero M. (in press) Flower emasculation accelerates ovule degeneration and reduces fruit set in sweet cherry. Scientia Horticulturae

Herrero M. (2000) Changes in the ovary related to pollen tube guidance. Annals of Botany, 85 (Suppl. A), 79-85.

Herrero M. (2003) Male and female synchrony and the regulation of mating in flowering plants. Philosophical Transactions of the Royal Society of London Series B- 
Biological Sciences, 358, 1019-1024.

Herrero M., Hormaza J.I. (1996) Pistil strategies controlling pollen tube growth. Sexual Plant Reproduction, 9, 343-347.

Heslop-Harrison Y. (2000) Control gates and micro-ecology: The pollen-stigma interaction in perspective. Annals of Botany, 85 (Suppl. A), 5-13.

Hormaza J.I., Herrero M. (1996) Dynamics of pollen tube growth under different competition regimes. Sexual Plant Reproduction, 9, 153-160.

Hughes J., McCully M.E. (1975) The use of an optical brightener in the study of plant structure. Stain Technology, 50, 319.

Jefferies C.J., Belcher A.R. (1974) A fluorescent brightener used for pollen tube identification in vivo. Stain Technology, 49, 199-202.

Johansen D.A. (1940) Plant Microtechnique. New York, NY: McGraw-Hill.

Kovaleva L., Zakharova E. (2003) Hormonal status of the pollen-pistil system at the progamic phase of fertilization after compatible and incompatible pollination in Petunia hybrida L. Sexual Plant Reproduction, 16, 191-196.

Kuhn B.F. (2006) Determination of starch in ovules of the sour cherry Cv. 'Stevnsbaer'. European Journal of Horticultural Science, 71, 120-124.

Lamp B.M., Connell J.H., Duncan R.A., Viveros M., Polito V.S. (2001) Almond flower development: floral initiation and organogenesis. Journal of the American Society for Horticultural Science, 126, 689-696.

Lebon G., Duchene E., Brun O., Magne C., Clement C. (2004) Flower abscission and inflorescence carbohydrates in sensitive and non-sensitive cultivars of grapevine. Sexual Plant Reproduction, 17, 71-79.

Linskens H.F., Esser K. (1957) Über eine spezifische Anfärbung der Pollen-Schläuche und die Zahl Kallosepfropen nach Selbstung und Fremdung. Naturwissenschaften, 44, 
16.

Pimienta E., Polito V.S., Kester D.E. (1983) Pollen tube growth in cross- and self-pollinated 'Nonpareil' almond. Journal of the American Society for Horticultural Science, 108, 643-647.

Robbie F.A., Atkinson C.J. (1994) Wood and tree age as factors influencing the ability of apple flowers to set fruit. Journal of Horticultural Science, 69, 609-623.

Robbie F.A., Atkinson C.J., Knight J.N., Moore K.G. (1993) Branch orientation as a factor determining fruit set in apple trees. Journal of Horticultural Science, 68, 317-335.

Rodrigo J., Herrero M. (1996) Evaluation of pollination as the cause of erratic fruit set in apricot 'Moniqui'. Journal of Horticultural Science, 71, 801-805.

Rodrigo J., Herrero M. (1998) Influence of intraovular reserves on ovule fate in apricot (Prunus armeniaca L.). Sexual Plant Reproduction, 11, 86-93.

Rodrigo J., Herrero M. (2002a) The onset of fruiting in apricot (Prunus armeniaca L.). Journal of Applied Botany, 76, 13-19.

Rodrigo J., Herrero M. (2002b) Effects of pre-blossom temperatures on flower development and fruit set in apricot. Scientia Horticulturae, 92, 125-135.

Rodrigo J., Hormaza J.I., Herrero M. (2000) Ovary starch reserves and flower development in apricot (Prunus armeniaca). Physiologia Plantarum, 108, 35-41.

Sedgley M. (1980) Anatomical investigation of abscissed avocado flowers and fruitlets. Annals of Botany, 46, 771-777.

Shykoff J.A. (1992) Sex polymorphism in Silene acaulis (Caryophyllaceae) and the possible role of sexual selection in maintaining females. American Journal of Botany, 79, 138-143.

Stephenson A.G. (1981) Flower and fruit abortion: proximate causes and ultimate functions. Annual Review of Ecology and Systematics, 12, 253-279. 
Stephenson A.G., Bertin R.I. (1983) Sexual selection in plants. In Pollination Biology, pp. 109-150. Ed Real L. New York, NY: Academic Press.

Sterling C. (1964). Comparative morphology of the carpel in the Rosaceae. 1. Prunoideae: Prunus. American Journal of Botany, 51, 36-44.

Sukhvibul N., Whiley A.W., Smith M.K., Hetherington S.E., Vithanage V. (1999) Effect of temperature on inflorescence and floral development in four mango (Mangifera indica L.) cultivars. Scientia Horticulturae, 82, 67-84.

Weterings K., Pezzotti M., Cornelissen M., Mariani C. (2002) Dynamic 1aminocyclopropane-1-carboxylate-synthase and -oxidase transcript accumulation patterns during pollen tube growth in tobacco styles. Plant Physiology, 130, 11901200.

Wilcock C., Neiland R. (2002) Pollination failure in plants: why it happens and when it matters. Trends in Plant Science, 7, 270-277.

Williams R.R. (1965) The effect of summer nitrogen applications on the quality of apple blossom. Journal of Horticultural Science, 40, 31-41.

Williams J.L., Conner J. K. (2001) Sources of phenotypic variation in floral traits in wild radish, Raphanus raphanistrum (Brassicaceae). American Journal of Botany, 88, $1577-1581$.

Yang C.F., Guo Y.H., Gituru R.W., Sun S.G. (2002) Variation in stigma morphology - how does it contribute to pollination adaptation in Pedicularis (Orobanchaceae)? Plant Systematics and Evolution, 236, 89-98. 
Table 1 One-way analysis of variance (ANOVA) of stigmatic area, total and germinating pollen grains in set and abscised flowers of apricot 'Moniqui'. * Significant at $P<0.05$, SS: sum of squares, df: degrees of freedom, MS: mean of squares

\begin{tabular}{llrrrrc}
\hline Variable & Source & SS & df & MS & $F$ & $P$ \\
\hline Stigmatic area & Between Groups & 0.075 & 1 & 0.074 & 9.13 & $0.003^{*}$ \\
& Within Groups & 0.911 & 111 & 0.008 & & \\
Total pollen grains & Total & 0.986 & 112 & & & \\
& Between Groups & 11586 & 1 & 10949 & 4.84 & $0.03^{*}$ \\
& Within Groups & 253763 & 106 & 2394 & & \\
Germinating pollen grains & Total & 265349 & 107 & & & \\
& Between Groups & 48867 & 1 & 4887 & 6.05 & $0.015^{*}$ \\
& Within Groups & 85599 & 106 & 807 & & \\
& Total & 90486 & 107 & & & \\
\hline
\end{tabular}


Table 2 Backward stepwise multiple regression analysis using Generalized Linear Models. Wald statistic, associated $P$-value, and step at which variables were removed from / kept in the model are shown for each of the eight variables measured in flowers of apricot 'Moniqui'

\begin{tabular}{lccc}
\hline \multicolumn{1}{c}{ Trait } & Step & Wald statistic $(1 \mathrm{df})$ & $P$ \\
\hline Pollen tubes at 1/2 of the style & 1 & 0.095 & 0.757 \\
Pollen tubes at 3/4 of the style & 2 & 0.094 & 0.758 \\
Pollen grains on the stigma & 3 & 0.597 & 0.439 \\
Pollen grains germinated & 4 & 0.937 & 0.333 \\
Pollen tubes at the transmitting tissue & 5 & 0.859 & 0.354 \\
Pollen tubes at 1/4 of the style & 6 & 1.506 & 0.220 \\
Stigmatic area $\left(\mathbf{m m}^{2}\right.$ ) & $\mathbf{7}$ & $\mathbf{4 . 5 9 3}$ & $\mathbf{0 . 0 3 2}$ \\
Pollen tubes at the ovary & $\mathbf{7}$ & $\mathbf{4 . 9 4 0}$ & $\mathbf{0 . 0 2 6}$ \\
\hline
\end{tabular}


Table 3 Percentage of flowers with starch, and univariate analysis to assess differences in number of xylem vessels and number of cells in stylar sections of set and abscised flowers in apricot 'Moniqui'.*: significant at $\mathrm{p}<0.05$, SE: standard error, df: degrees of freedom, $F$ : $F$ statistic, NS: no significant

\begin{tabular}{|c|c|c|c|c|c|c|c|c|c|}
\hline Trait & & Set flc & wer & & & cisec & flov & ers & $F$ \\
\hline Flowers with starch (\%) & $\begin{array}{c}\text { Mean } \\
100\end{array}$ & $\mathrm{SE}$ & $\mathrm{df}$ & Range & $\begin{array}{c}\text { Mean } \\
53\end{array}$ & $\mathrm{SE}$ & df & Range & \\
\hline Number of xylem vessels & 39.3 & 1.7 & 8 & $35-46$ & 34 & 1.1 & 8 & $31-40$ & $7.42 *$ \\
\hline Number of cells & 21.2 & 0.7 & 8 & $19-24$ & 20.2 & 0.9 & 8 & $16-25$ & $0.51 \mathrm{NS}$ \\
\hline
\end{tabular}




\section{Figure legends}

Figure 1 Pollen tube growth in apricot 'Moniqui' in field conditions during 6 days following pollination. (A) Percentage of style length reached by the longest pollen tube. (B) Percentage of flowers with pollen tubes at the base of the style.

Figure 2 Fruit abscission in apricot 'Moniqui' in control and treated flowers. Percentage of fruits remaining in the trees from the original number of flowers (left) and percentage of fruits dropped each week in relation to the initial number of flowers (right) in a population of flowers left as control (A, B) and in two populations of flowers whose styles were cut off 5 $(\mathrm{C}, \mathrm{D})$ and 6 (E, F) days after pollination. Hand-pollinated $(O)$ and non pollinated flowers $(\mathrm{O})$.

Figure 3 Comparison among stigma surface and number of total and germinated pollen grains at the stigma in set and abscised flowers of apricot 'Moniqui'. The three variables follow the same pattern and show significant differences between set $(n=58)$ and abscised flowers $(\mathrm{n}=55)$ at $P<0.05$. Means \pm SE of the average values.

Figure 4 Distribution of both set $(n=58)$ and abscised $(n=55)$ flowers of apricot 'Moniqui' in classes according to stigmatic area (A) and number pollen grains at the stigma (B), and percentage of fruit survival for each class $(\mathbf{O})$.

Figure 5 Transversal style sections showing the cortical tissue formed by elongated cells (A) and a compact transmitting tissue (TT) enveloped by vascular bundles (arrows) (B) and pollen tubes growing through the style (C) and reaching the base of the style (D). Calcofluor- (A) and 
Acridine orange-stained (B) transverse sections of the style. Aniline blue staining of squash preparations (C and D). A, C, D: Scale bar $=50 \mu \mathrm{m}$. B: Scale bar $=20 \mu \mathrm{m}$.

Figure 6 Number of pollen tubes (A) and percentage of pollen tubes in relation to the initial number at the transmitting tissue entrance (B) at each level of the style in set $(n=58)$ and abscised flowers $(n=51)$ of apricot 'Moniqui'. Means \pm SE of the average values. 
Fig. 1

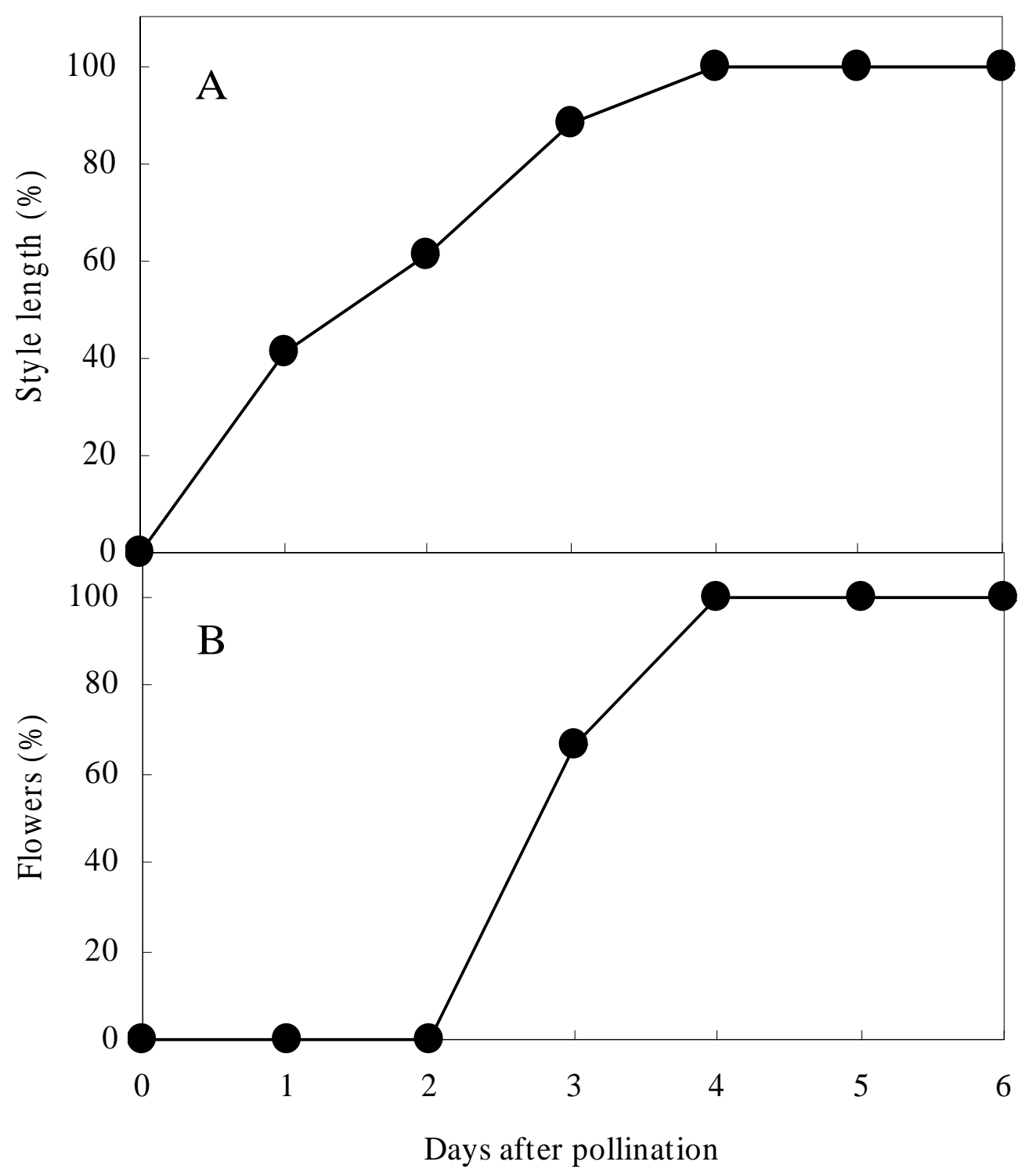


Fig. 2

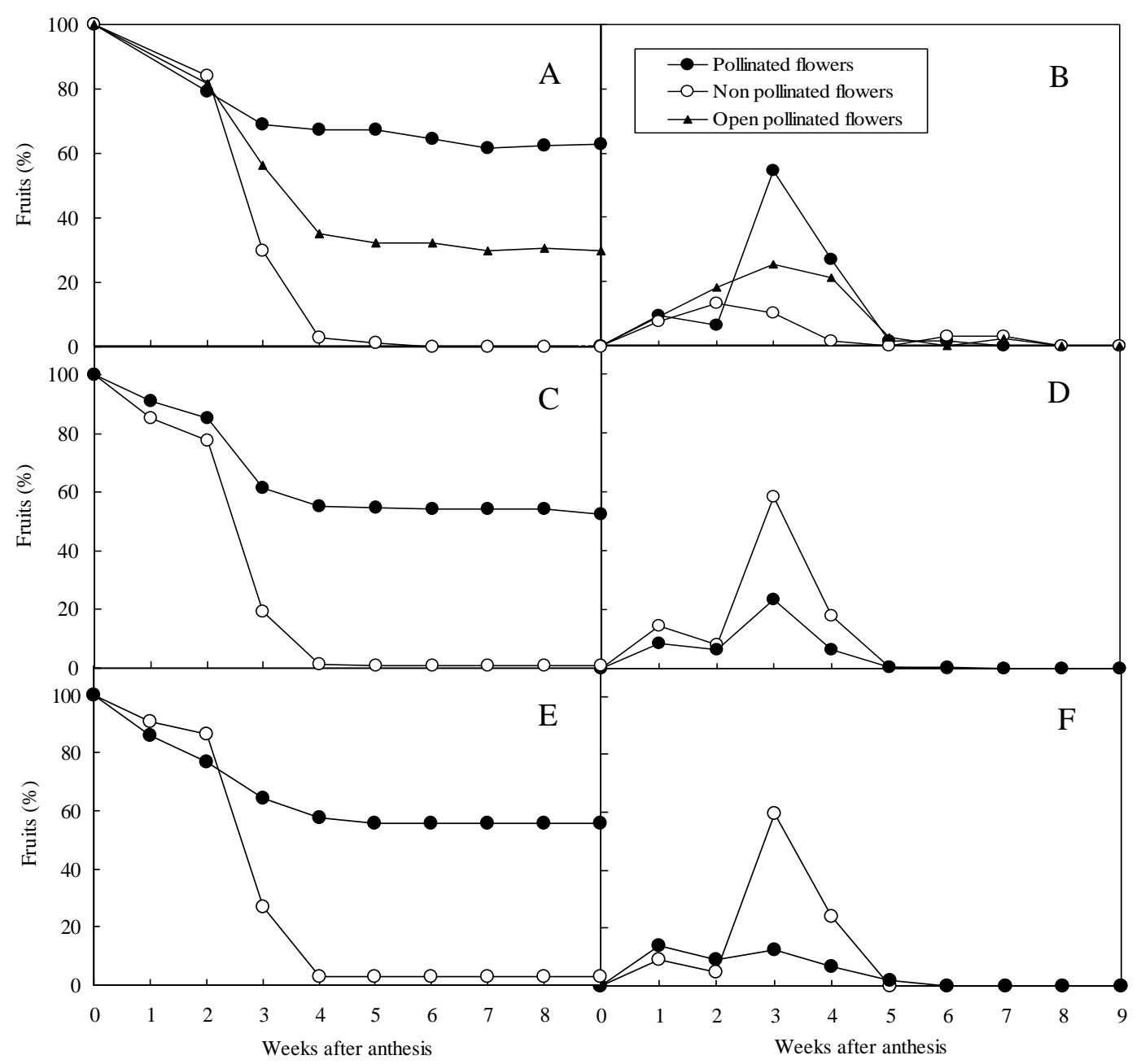


Fig. 3

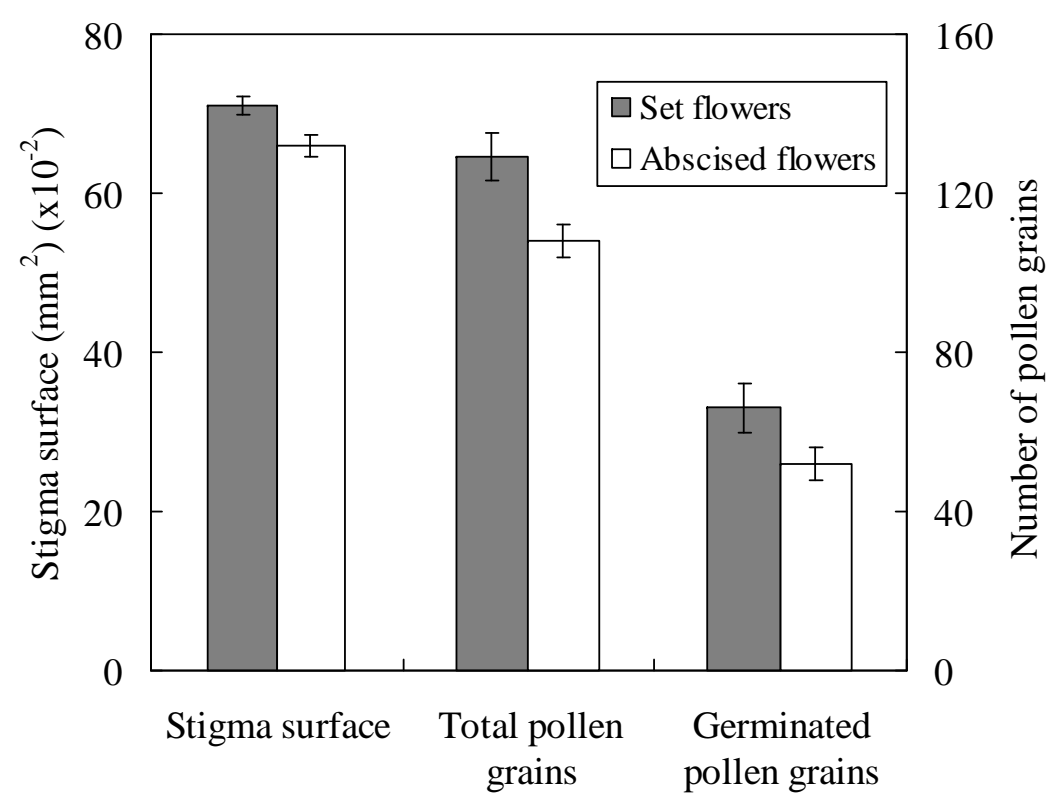


Fig. 4
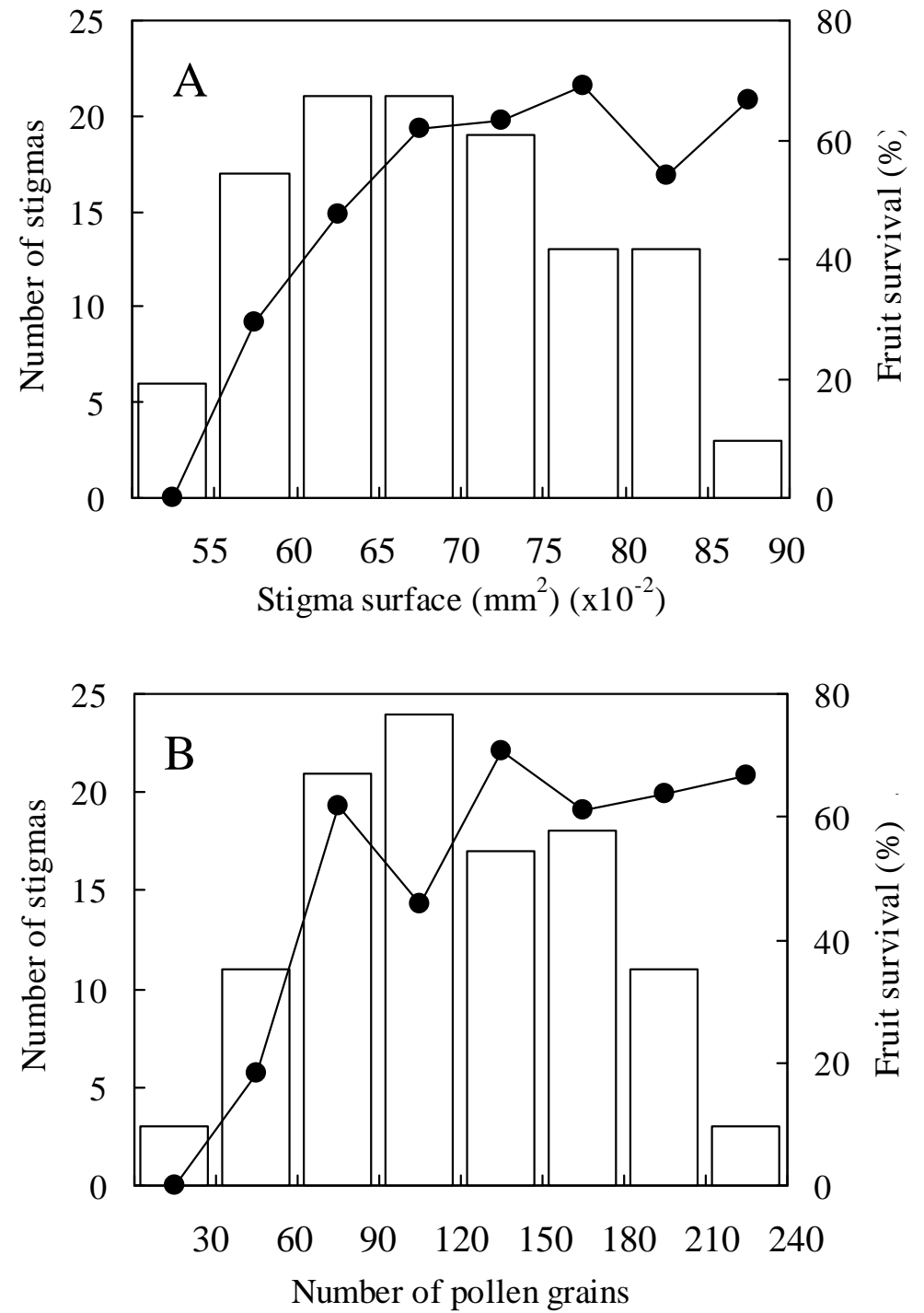
Fig. 5
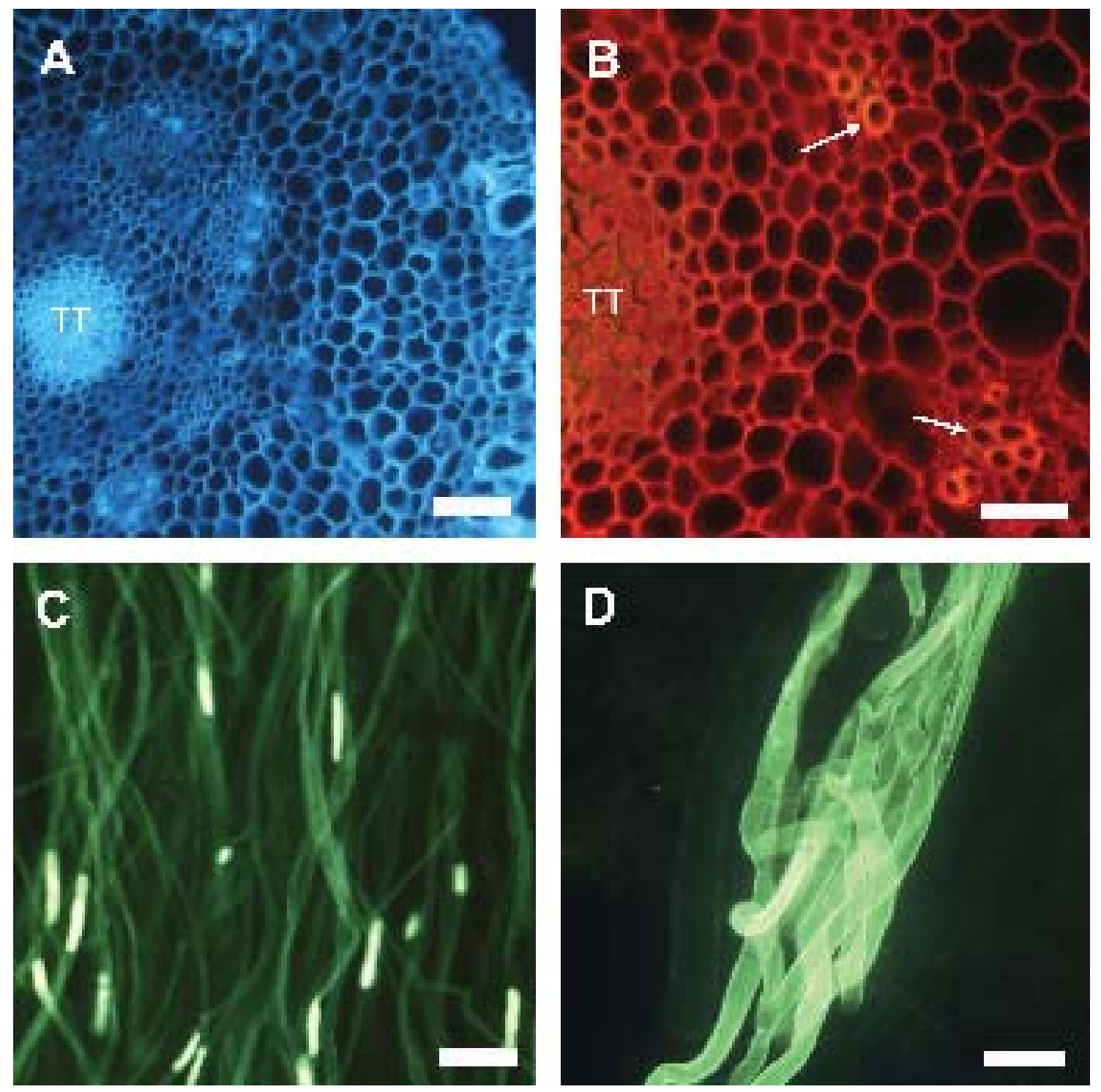
Fig. 6

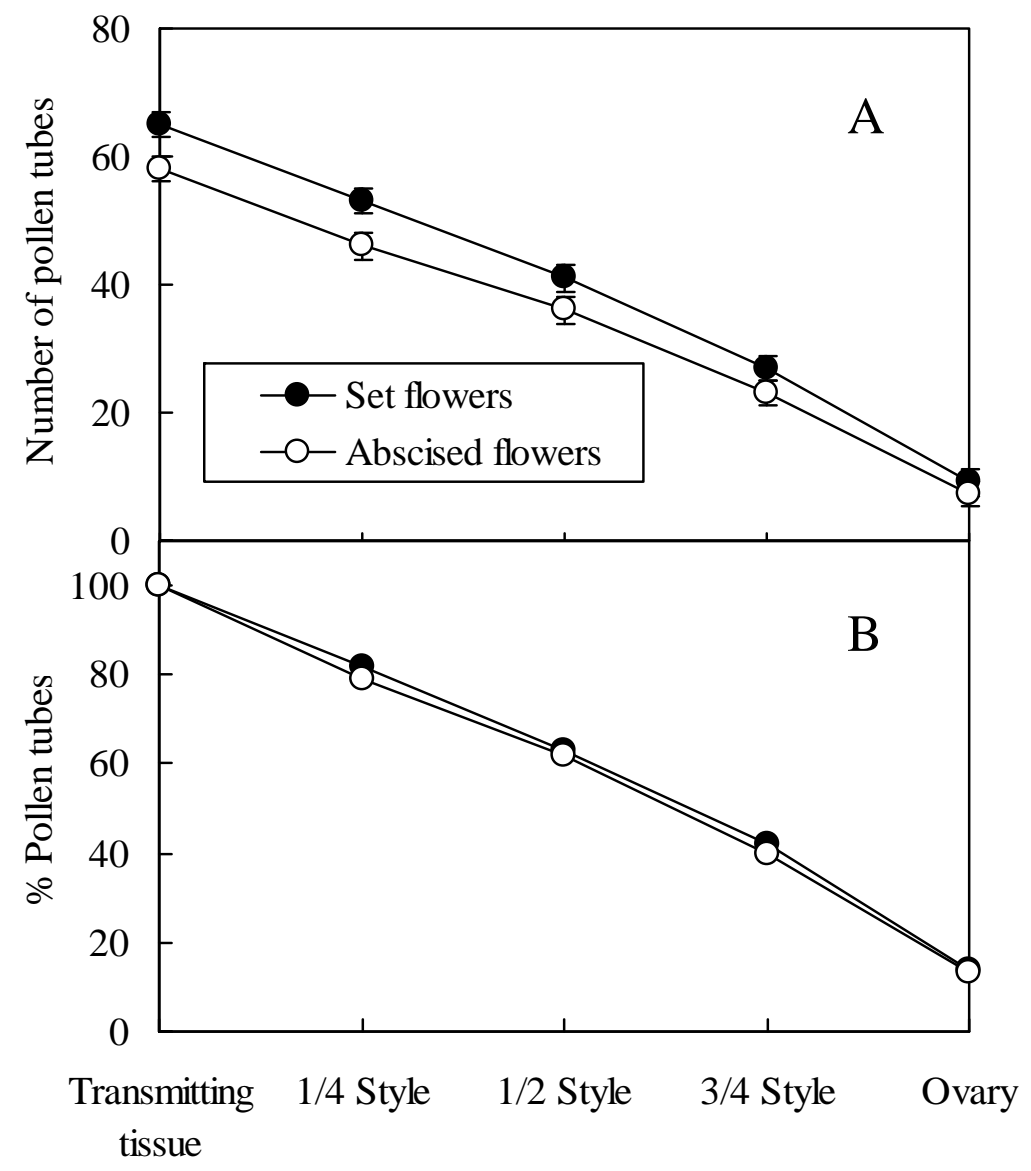

